\title{
EL ODIO HACIA LA MUJER COMO MÓVIL DE LA TRAGEDIA EN ORESTES DE EURÍPIDES
}

\author{
Cecilia Perczyk ${ }^{1}$ \\ Universidad Nacional de Hurlingham, Argentina \\ ceciliaperczyk@ hotmail.com \\ ORCID: 0000-0003-3521-5784
}

Gabriel Lombardi

Universidad de Buenos Aires, Argentina

gabrielombardi@gmail.com

ORCID: 0000-0002-0571-3208

DOI: 10.17533/udea.affs.v16n31a05

Agradecimiento

Agradecemos a la profesora María Belén Landa por la

orientación en el trabajo con

Aristóteles y el tema de las emociones.

1 Licenciada en Psicología (UBA). Magister en Estudios Clásicos (UBA). Doctora en Letras Clásicas (UBA). Se especializa en filología y tragedia griegas. El tema de investigación que desarrolla es la tragedia como fuente para una arqueología de la locura en la Grecia clásica y por su formación aplica herramientas del psicoanálisis. Es profesora de literatura clásica. Docente de las universidades: Universidad Nacional de Hurlingham y Universidad Nacional de San Martín. Becaria posdoctoral de CONICET.

2 Gabriel Lombardi es Médico (UBA). Doctor en Psicología (UBA). AME de la Escuela de Psicoanálisis de los Foros del Campo Lacaniano. Es profesor titular de Clínica de Adultos en la Facultad de Psicología de la UBA, casa en la que dirige el Instituto de Investigaciones. Su campo de investigación principal es la clínica psicoanalítica, con particular énfasis en los métodos y la ética del psicoanálisis. 


\section{Resumen}

En la tragedia Orestes de Eurípides se representan los sucesos acontecidos en la ciudad de Argos luego del asesinato de Clitemnestra. El protagonista de la obra es el matricida Orestes, a quien se lo muestra sumamente excitado en la planificación de un nuevo crimen, el de Helena y su hija Hermíone. En el presente trabajo nos proponemos analizar el odio a la mujer como el móvil de la trama desde la teoría psicoanalítica de orientación lacaniana. El desprecio se constituye como un antecedente de la acción trágica al trasladarse de Clitemnestra hacia Helena, figura emblemática de la mitología griega por ser considerada la mujer más hermosa.

Palabras clave: Eurípides, Orestes, odio, mujer.

\section{HATRED TOWARDS THE WOMAN AS MOTIVATION OF THE TRAGEDY IN EURIPIDES' ORESTES}

\section{Abstract}

In Euripides' tragedy Orestes are represented the events occurred in the city of Argos after the murder of Clytemnestra. The main character of the play is the matricide Orestes, who is displayed extremely excited in the planning of a new crime, the one of Helena and her daughter Hermione. This paper aims to analyze hatred towards the woman as motivation of the plot from the psychoanalytic theory of Lacanian orientation. Contempt becomes an antecedent of the tragic action by moving from Clytemnestra towards Helena, emblematic figure of Greek mythology for being considered as the most beautiful woman.

Keywords: Euripides, Orestes, hatred, woman.

\section{LA HAINE ENVERS LA FEMME EN TANT QUE MOBILE DANS ORESTE D'EURIPIDE}

\section{Résumé}

La tragédie Oreste d'Euripide présente les événements qui ont eu lieu à Argos après le meurtre de Clytem- nestre. Le protagoniste de l'œuvre est le matricide Oreste, qui est dépeint comme quelqu'un de très excité pla- 
nifiant un nouveau crime, celui d'Hé- de l'action tragique puisqu'il passe de lène et de sa fille Hermione. Ce texte a Clytemnestre à Hélène, figure emblépour but d'analyser la haine envers la matique de la mythologie grecque car femme en tant que mobile de la trame considéréecommela plus bellefemme. sous l'angle de la théorie psychanalytique à orientation lacanienne. Le Mots-clés : Euripide, Oreste, haine, mépris apparaît comme antécédent femme.

Recibido:07/08/2018 • Aprobado:25/03/2019 


\section{Introducción}

En la tragedia Orestes de Eurípides se representan los hechos transcurridos en Argos luego del asesinato de Clitemnestra a manos de su hijo, crimen cometido para vengar la muerte del padre, Agamenón. ${ }^{3}$ Tras el discurso del mensajero sobre la asamblea donde condenan a la lapidación a Orestes y su hermana Electra, el público asiste a la planificación del asesinato de Helena, hermana de Clitemnestra, y de su hija Hermíone. Se trata de una propuesta de Pílades, amigo desde la infancia de Orestes, avalada por Electra y que provoca en el joven un profundo estado de excitación. ${ }^{4}$

En el presente trabajo nos detendremos en la función del odio como antecedente de la acción trágica conformada por el crimen de Helena, un dato que la crítica parece no haber tomado en cuenta. ${ }^{5}$ El desprecio que siente Orestes hacia Clitemnestra, consecuencia del asesinato del padre, se traslada en la tragedia de Eurípides hacia la figura de Helena. El nuevo asesinato se justifica con un argumento que consiste en la valoración negativa del personaje como causa de la guerra de Troya. La planificación y ejecución del crimen conforman una innovación dramática respecto del mito y por su naturaleza no tradicional exigen, para que la obra sea plausible, la elaboración de circunstancias y motivaciones personales que, es nuestra hipótesis, el psicoanálisis permite esclarecer. ${ }^{6}$

3 Agamenón, rey de Argos, y Menelao, rey de Esparta, eran hijos de Atreo, por lo cual suele hablarse de ellos con el patronímico "Atridas".

4 Sobre el mito de Orestes se han conservado obras de los tres trágicos: la trilogía Orestía de Esquilo, compuesta por Agamenón, Coéforas y Euménides; Electra de Sófocles, y Electra e Ifigenia entre los Tauros de Eurípides, además de Orestes.

5 Según Willink (1986, pp. xxxi-xxxii), la traición de Menelao constituye una motivación apropiada para asesinar a Helena. En cuanto al matricidio, Mc. Hardy (2008, pp. 110-111) analiza las tragedias conservadas de los tres trágicos y sostiene que la búsqueda de venganza por parte de Orestes se relaciona principalmente con el deseo de recibir su herencia y alcanzar el poder.

6 La versión de Esquilo acerca del mito de Orestes ha recibido mayor atención por parte del psicoanálisis que la de Eurípides. Freud (1939/2001, p. 110) menciona Orestía en relación con la idea de Bachofen, teórico del siglo XIX, sobre el pasaje del matriarcado al patriarcado. La saga de los Atridas adquiere el valor de una ale- 
A diferencia de otras lecturas de textos clásicos realizadas desde el psicoanálisis, no nos proponemos un ejercicio de psicoanálisis aplicado. ${ }^{7}$ Establecer un lazo causal entre la biografía del autor y su producción sería sumamente dificultoso por tratarse de un autor de la Antigüedad. Tampoco interesa establecer un diagnóstico del personaje dramático, como lo realizaron algunos especialistas del área de la salud mental y otros orientados a la filología griega. ${ }^{8}$ Dado que no se trata de un historial clínico, sino de una obra de teatro compuesta para ser representada ante un público en un certamen, su autor no se atiene a la configuración típica de las enfermedades, si bien resulta notable la riqueza de la descripción y la presencia de terminología propia de los textos médicos de la época. ${ }^{9}$ Nuestro objetivo consiste en aportar a la exégesis del texto de modo tal que se ofrezcan herra-

goría político-religiosa de la transición de un sistema al otro. Por su parte, Klein (1976/1963) aborda la diversidad de roles simbólicos que encarnan los personajes de Orestía; allí Clitemnestra simboliza "el pecho malo" y Atenea "el pecho bueno". En tanto, Green (1982/1969, pp. 65-66) señala que los psicoanalistas deberían tomar como modelo, además del ciclo tebano, el de Argos, puesto que en ambos casos el tema central son las relaciones entre los padres y los hijos.

7 Desde sus inicios el psicoanálisis se relaciona con el mundo griego. El complejo de Edipo se funda en la lectura realizada por Freud de Edipo Rey de Sófocles. Lacan (1992/1973) sienta las bases de la noción de "deseo puro" a partir de la lectura de otra tragedia de Sófocles, Antígona. Véase Zafiropoulos (2010 y 2017a), que sostiene que el método de trabajo de Lacan es el de un mitólogo.

8 Así lo hizo Dracoulides (1952), psicoanalista abocado al análisis de artistas y sus obras, al desarrollar un diálogo imaginario con el personaje del hijo de Agamenón, que intenta emular un interrogatorio psicodiagnóstico. En tanto Simon (1984, pp. 126-127), psiquiatra norteamericano que estudia la locura en la Antigüedad, explica que, mientras en la versión de Esquilo se podía hablar de una melancolía nociva, en el protagonista de Orestes predomina la enfermedad de la paranoia. Lorenzi (2015, p. 4), desde una perspectiva psicopatológica, afirma que se trata de una personalidad "borderline". Por otra parte, desde los estudios clásicos, Ferrini (1978, p. 50) sostiene que el objetivo de Eurípides es presentar a Orestes como un epiléptico. Para Aélion (1983, p. 246), los síntomas descriptos en Orestes constituyen un cuadro de fiebre más que un estado de locura y entiende que el trágico en lugar de focalizar en la manifestación de la crisis, se ocupa de describir los estragos provocados en el organismo.

9 La relación entre género trágico y medicina hipocrática ha sido objeto de numerosos estudios. En un primer momento se destacó la coincidencia lexical (Ciani, 1974, pp. 70-110; Ferrini, 1978, pp. 49-62). Los estudios más actuales identificaron 
mientas para comprender el actuar de Orestes, por lo cual nos enfocaremos en los discursos de los personajes dentro del marco de la obra estudiada. ${ }^{10} \mathrm{El}$ acto es tal porque " (...) tiene el lugar de un decir, cuyo sujeto cambia" (Lacan, 2001/1969, p. 375), y ese decir, se deduce de los dichos (Lacan, 2001/1972, passim). En especial, trabajaremos aquellos pasajes donde se aprecia el surgimiento del odio -considerado por Lacan en su primera enseñanza como una de las tres pasiones fundamentales del ser, junto con el amor y la ignorancia- ${ }^{11}$ y el valor particular que adquiere al focalizarse en las figuras femeninas. ${ }^{12} \mathrm{Si}$ el amor, explica Soler (2010), es la búsqueda de ser para un ser que faltade-ser; el odio, su sombra, apunta a este falta-de-ser en su destructi-

que comparten ideas sobre el papel del sufrimiento, la enfermedad y la naturaleza de la curación en la vida del hombre (Clarke- Kosak, 2004, y Holmes, 2010).

10 Con intenciones similares a las nuestras, pero desde una perspectiva psicoanalítica diferente, la helenista Zeitlin (1981, pp. 64-67) entiende que el protagonista de Orestes recrea el trauma una y otra vez, de manera tal que la repetición se configura como la irónica garantía de su identidad. Para su interpretación se basa en la lectura que hace Lichtenstein del concepto freudiano de "compulsión a la repetición", para quien dicha compulsión no pertenece a la esfera de la pulsión de muerte, sino que es una manifestación de la necesidad de mantener la identidad.

11 Lacan (1998/1975, p. 394) señala que la pasión del odio se inscribe en la unión de lo imaginario y lo real. Al sistematizar su teoría estructural mediante nudos, ubica allí la angustia (Lacan, 1974-1975).

12 En el libro II de Retórica, Aristóteles lleva adelante un estudio sistemático de las pasiones, entre las que incluye el odio. Las pasiones son por las cuales (los hombres) difieren cambiando en lo relativo a sus decisiones, a las que siguen dolor y placeres, como por ejemplo, la cólera, la compasión, el temor y cuantas otras de naturaleza semejan-

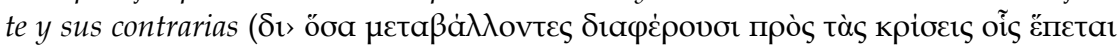

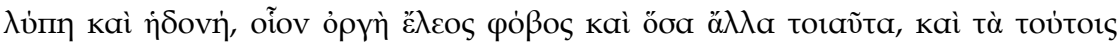
Ėvavtia, 1378a 19-21). El pasaje citado de Retórica de Aristóteles corresponde a la edición de Ross (1964) y la traducción del texto griego nos pertenece. Cabe señalar que el término páthos ha sido traducido al español por "pasión" y, también, por "emoción". El filósofo explica que el odio constituye la reacción contraria al amor y para su denominación emplea términos provenientes de dos familias de palabras diferentes (1382a). Por un lado, usa aquella vinculada a ह̌ $\chi \emptyset 0$, cuyo sentido se relaciona con la idea de enemistad en tanto enemigo personal, ya que para enemigo militar en griego se emplea по $\lambda \dot{\varepsilon} \mu 10$, termino derivado de пó $\lambda \varepsilon \mu о \varsigma$, "guerra". Por otro lado, emplea piøeĩv, vocablo ligado a la falta de aceptación, del cual proviene $\mu$ tooyovia, "odiar a la mujer", de donde deriva nuestra palabra "misoginia". 
vidad. Se dirige al ser del otro, hacia su unicidad singular, y establece una relación de execración.

Hacia el final introduciremos una viñeta clínica con el objetivo de señalar similitudes formales entre el método psicoanalítico y el desarrollo dramático, en particular sobre el tema del presente trabajo. Veremos cómo, al igual que Orestes, un psicótico en análisis traslada el odio a su madre hacia un nuevo objeto, su tía materna. Para llevar a cabo nuestra tarea, seguiremos las indicaciones de Freud (2001/1917) para la tragedia de Edipo Rey de Sófocles, aplicable a otras tragedias como la que aquí estudiamos:

la obra del dramaturgo ateniense figura el proceso por el cual el crimen de Edipo, cometido hace tiempo, se revela poco a poco, merced a una indagación diferida con maestría y desplegada mediante nuevos y nuevos indicios; en esa medida, semeja la marcha de un psicoanálisis. (p. 301).

\section{La trama de la tragedia griega}

La tragedia abre con un discurso a cargo de Electra en el que se informa la cadena de desdichas de su familia, que comenzó con el fundador de la estirpe de nombre Tántalo. Luego la joven expone la situación actual en la que Orestes se ve consumido por la locura, enfermedad relacionada desde su origen con el matricidio. Así, la locura del protagonista queda inscripta en una lógica familiar. ${ }^{13}$ Tras mencionar la condena a muerte que pesa sobre ella y su hermano, Electra expre-

13 En el género trágico, y especialmente en la obra de Eurípides, se exponen diferentes versiones acerca del origen de la manía de los personajes. Si bien el fenómeno aparece personificado en deidades, surgen otros causantes. Así en Orestes no solo se atribuye la causa de la enfermedad a las Erinias y a otras divinidades sin especificar (vv. 38, 531-532 y 844-846), además de que se remite a la contaminación provocada por la sangre (vv. 36-37, 337-338 y 400), sino que se ubican procesos mentales en el origen (vv. 396 y 398). Por lo que entendemos, al igual que Ciani (1974, p. 98) y Medda (Eurípides, 2001, pp. 29-30), que conviven causas naturales y divinas. En cambio, Aélion (1983, p. 247) y Assaël (1993, p. 138) sostienen la motivación interna de la enfermedad. Por su parte, Padel (2005/1995, p. 74) habla únicamente de un origen divino. 
sa la esperanza que le provoca la llegada a la ciudad de Menelao. La solicitud se explicitará en el segundo episodio y constituye el primer plan de acción para la salvación. Menelao tiene una deuda para con el padre de Orestes: Agamenón lo había ayudado en la búsqueda de su esposa Helena (Eurípides, 1994, vv. 241-244). En una sociedad como la griega, basada en un sistema de dones y contradones, haber recibido un favor provocaba un compromiso.

Menelao no llega solo a Argos, sino que lo hace acompañado justamente de su esposa. Electra señala que Helena debió esperar a la noche para salir por el temor de ser agredida por los parientes de los soldados caídos en Troya (Eurípides, 1994, vv. 56-60). El prólogo cierra con un diálogo entre Electra y la recién llegada, que dice encontrarse afectada por la muerte de su hermana Clitemnestra. Helena expresa el miedo que le ocasiona que la vean los argivos debido a los muertos que ocasionó (v. 102). ${ }^{14}$ Tras la entrada del Coro, que se lamenta de la situación de los hijos de Agamenón, el público asiste al primer episodio, donde se pone especial énfasis en el deterioro de Orestes. Tendido en el lecho, el joven solicita los cuidados de su hermana. La postración del personaje es tal que se habla de él como si se tratara de un cadáver.

Inmediatamente, luego de informar acerca de la llegada de Menelao y Helena a la ciudad, Electra señala el cambio repentino en su hermano:

Electra: ¡Ay, hermano! Tu mirada se perturba, rápido pasaste a la furia, mientras hace un momento eras sensato.

Orestes: ¡Madre! Te suplico, no instigues contra mí a las doncellas de mirada sanguinaria y aspecto de serpientes. Pues estas, estas saltan cerca de mí. (West, 1996, vv. 253-257). ${ }^{15}$

14 "Argivo" es el gentilicio para los habitantes de la ciudad de Argos, cuyo rey había sido Agamenón.

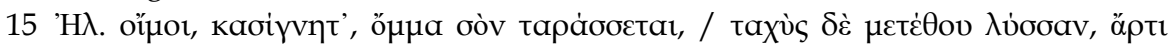

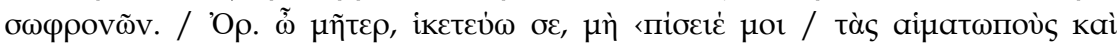

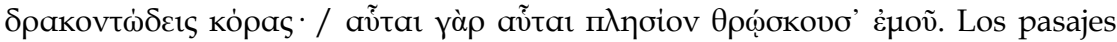
citados de Orestes de Eurípides corresponden a la edición de Diggle (1994) y la traducción de los textos griegos nos pertenece en todos los casos. 
El auditorio se encuentra con un primer plano del matricida preso de alucinaciones cuyo objeto son las Erinias. ${ }^{16}$ La crítica se divide acerca de la causa de la crisis. Para Di Benedetto (Eurípides, 1965, p. 53) se produce sin aparente justificación. En cambio, para Holmes (2010, p. 249) y Gambon (2016, pp. 40-41), con quienes acordamos, la crisis es provocada por la mención de la llegada de Helena. Su presencia tiene para Orestes serias consecuencias. ${ }^{17}$

Luego de un breve estásimo en el que el Coro lamenta la presencia de las Erinias, se asiste al encuentro de Orestes y Menelao. El Atrida señala que está al tanto del crimen de Agamenón a manos de su esposa y se muestra preocupado ante el estado de su sobrino. Sigue un duro agón entre Orestes y Tíndaro, su abuelo por parte de madre. ${ }^{18} \mathrm{El}$ anciano se presenta como un defensor de las instituciones de la ciudad: rechaza la justicia por mano propia y exige que se someta a la decisión de la asamblea la situación de sus nietos. Considera justa la muerte de Clitemnestra, pero señala que no debería haber muerto a manos de su propio hijo (vv. 496-506 y 538-539), retomando una normativa ateniense. En Atenas los esposos o sus parientes no debían matar a la mujer infiel sin el permiso de su padre o hermanos por el peligro de la contaminación (Demóstenes 59.87 y Lisias 14.28) (Mc. Hardy, 2008, pp. 46 y 111). Asimismo, Tíndaro indica que odia a Clitemnestra por haber matado a su marido y que considera a Helena una mujer malvada (vv. 518-522). Orestes intenta una argumentación tradicional: para defender el honor de su padre, que lo engendró, mató a su madre, quien simplemente lo dio a luz y alimentó (vv. 552-556). El otorgamiento a los hombres del papel protagónico en la procreación constituye una idea compartida de las sociedades tradi-

16 Las Erinias son divinidades primigenias nacidas de las gotas de sangre derramadas cuando Urano fue mutilado por Cronos (Hesíodo, Teogonía, vv. 183-187). Su ocupación consiste en provocar la locura a aquellos que asesinaron a un familiar.

17 Simon (1984: 127-131) sostiene que el protagonista de la tragedia mantiene hacía el género femenino una relación de ambivalencia que se advierte en la transformación de su hermana en una figura capaz de atacarlo cuando alucina en escena (vv. 264-265).

18 El término agón, "certamen" o "lucha", adquiere en el ámbito teatral el sentido específico de debate formal entre dos personajes. 
cionales, que encontramos en los tratados biológicos de Aristóteles (Héritier, 2007, pp. 19-20).

El joven explica el origen del odio hacia Clitemnestra: ${ }^{19}$ "y odiando a mi madre con justicia la maté, la que traicionó a un hombre cuando se fue de la casa con los hoplitas, como comandante de toda la tierra de la Hélade, y no mantuvo puro el lecho" (Eurípides, 1994, vv. 572-575). ${ }^{20}$ Se desprende del discurso que el desprecio por la madre y el matricidio resultan inescindibles para Orestes. En cuanto al tono, se vuelve más enfático con el correr de los versos. Incluso se refiere de modo directo a la infidelidad de Clitemnestra con Egisto, primo hermano de los Atridas que no participó de la expedición a Troya y se quedó en Argos. Completa la idea unos versos después al comparar a Clitemnestra con Penélope, que había esperado por 20 años a su marido en Ítaca sin contraer matrimonio (vv. 585-590). ${ }^{21}$

Orestes no logra disuadir a Tíndaro, sino más bien lo contrario. El anciano señala que partirá hacia la asamblea con el objetivo de promover la lapidación y destaca la participación de Electra en el cri-

19 Para Slater (1971, pp. 186-187 y 191-192), sociólogo norteamericano, el mito de Orestes constituye una historia de antagonismo sexual y conflicto entre madre e hijo que intenta solucionarse con la muerte de Clitemnestra. Explica que la de-

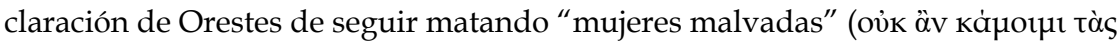

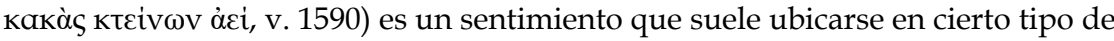
asesinos y revela la importancia de la seducción materna en la generación de una patología. Cf. Bunker (1944, pp. 198-207), traductor de varias obras de Freud al inglés, que se aboca a la cuestión del matricidio en los mitos griegos y concluye que el significado de asesinar a la madre es el de representar la relación sexual con ella.

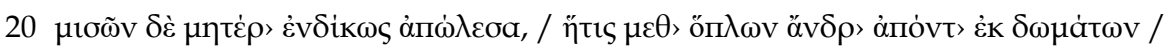

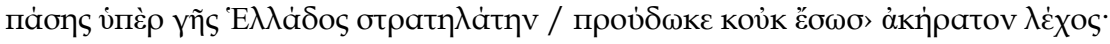

21 Agamenón contrasta la constancia de Penélope con el carácter traicionero de Clitemnestra, al recibir a los pretendientes en el Hades en el canto 24 de Odisea (Homero, 1963, pp. 191-202). NO CORRESPONDE ESA INFORMACION Además, en la Telemaquia (que corresponde a los primeros cuatro cantos de Odisea), se recurre en numerosas ocasiones a la figura de Orestes como modelo para Telémaco, de modo que para la audiencia griega los mitos de los dos jóvenes estaban ligados. 
men. ${ }^{22}$ Antes de retirarse, advierte a Menelao el peligro de defender "amigos impíos" (vv. 627-628); por lo cual el Atrida decide no ayudar a sus sobrinos con las armas y se justifica diciendo que llegó a Argos sin aliados. Sobre la falta de predisposición de Menelao para ayudar a sus sobrinos, a la cobardía tradicional del esposo de Helena se adosa la ambición de gobernar Argos (vv. 437 y 1058-1059) (Andrade en Eurípides, 2007, p. 25). De forma repentina aparece en escena Pílades, exiliado por su padre debido a su colaboración en el crimen de Clitemnestra, y le propone a Orestes ir a la asamblea a intentar convencer a los argivos de que no lo condenen a muerte. ${ }^{23}$

Un mensajero cuenta lo acontecido en la asamblea. Entre los discursos, en su mayoría condenatorios, destaca uno en oposición. Un campesino, al que no se lo identifica con un nombre, pero del que se dice que tiene una "vida irreprochable" (Eurípides, 1994, v. 922), sostuvo que Orestes debía ser coronado como rey de Argos y retoma para su argumentación el tema de la deshonra que ocasiona una esposa infiel. Seguidamente habló Orestes y a duras penas consiguió que no lo lapiden a cambio de prometer que se degollaría junto con su hermana. Tras escuchar el discurso de mensajero, Electra entona un lamento funerario por ella misma y su hermano, lo cual constituye una perversión del ritual puesto que quien lo entona es, al mismo tiempo, el objeto del lamento.

El tema del canto, al igual que en el prólogo, es el origen de la familia de los Atridas. Sigue un diálogo entre los hermanos en el que evalúan cómo morir. En ese momento irrumpe nuevamente Pílades y dice que morirá con ellos por haber participado en el crimen de Clitemnestra. Ahora bien, la participación de Pílades no se recorta a compartir el lamento. Como en el segundo episodio, hace una propuesta que consiste, en este caso, en tomar venganza de Menelao degollando con sus espadas a Helena, hospedada en el palacio junto con sus servidores bárbaros. De esta manera logra que su amigo no se suicide. Podría decirse que la planificación de un nuevo asesinato vivifica al protagonista de la tragedia. No es un dato menor para

22 Acerca del papel de Electra como instigadora del asesinato se extendieron Sófocles y Eurípides en sus versiones de Electra.

23 Pílades es el hijo de Estrofio con Anaxibia, hermana de Menelao y Agamenón. 
la interpretación de la obra que el actor que interpretaba a Pílades también actuaba de Apolo: ambos cumplen una función protectora para el protagonista de la tragedia. ${ }^{24}$ En el desarrollo de su propuesta, Pílades destaca que matando a Helena obtendrán el favor de los argivos y podrán salvarse. Además, para asegurarse de que se llevará a cabo el nuevo crimen, acota: “y no serás llamado el matricida, tras matarla, sino que perdiendo el calificativo, vas a dar con uno mejor, siendo llamado el asesino de la sanguinaria Helena" (vv. 1140-1142).$^{25}$ De manera que el joven adquirirá otro nombre a partir del nuevo crimen. Orestes alaba a su amigo y destaca la felicidad que le acarrea salvarse "matando sin morir" (v. 1174). Entonces Electra propone tomar de rehén a Hermíone en el caso de que Menelao pretenda tomar venganza por la muerte de Helena. La idea no es nueva, ya que unos versos antes, al dialogar con Menelao, Orestes le dice que no ocasione la muerte de su hija (v. 659). Nótese el hecho de que los asesinos de Clitemnestra son los mismos que ejecutan el crimen de Helena, pero con la diferencia de que ningún dios exige la muerte de la mujer de Menelao. La relación entre los asesinatos toma, por lo tanto, la forma de un quiasmo: mientras en el caso de madre de Orestes, una demanda divina se acompaña de una acción humana, un dios bloquea las acciones de los hombres en el de Helena, ya que serán detenidos por Apolo (Greenberg, 1962, p. 162-163).

La ejecución del crimen de Helena ocurre fuera de escena siguiendo las convenciones del teatro ático. No resultaba conveniente para los griegos que en el marco de una ceremonia religiosa de la polis, como lo era la representación teatral dedicada al dios Dioniso, se representara un espectáculo de sangre. Por lo cual, siguiendo las reglas del decoro, en el tercer estásimo Helena grita desde el interior del palacio y el Coro junto con Electra comentan la situación (1994, vv. 12471301). El éxodo comienza con la captura de Hermíone y sigue con la aparición del esclavo de Helena que informa los acontecimientos del

24 Cuando aparece el dios en escena, Pílades no habla más. Por lo cual Medda (Eurípides, 2001, pp. 76-78) sostiene que el primer actor interpretaba a Orestes y al mensajero, el segundo a Electra, Menelao y el frigio, el tercero a Helena, Tíndaro, Pílades, Hermíone y Apolo.

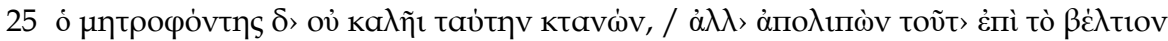

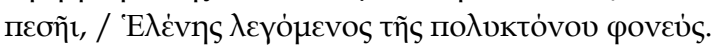


interior del palacio. Al llevar nuevamente al escenario el crimen de Helena, esta vez bajo la forma de la narración, se enfatiza su ejecución. Luego de un diálogo entre el esclavo y Orestes, llega Menelao con sus guardias al palacio para salvar a su hija, reclamar el cadáver de su esposa y encargarse de los asesinos, mientras los conspiradores se proponen incendiar el palacio. Ante la desesperación de Menelao, Orestes le ofrece no degollar a su hija si convence a los argivos de no matarlo a él y a su hermana (1994, vv. 1610-1611). Menelao suplica entonces a los habitantes de la ciudad que lo ayuden y en ese momento desciende Apolo, desde los cielos, para solucionar el conflicto.

\section{El alegato del crimen}

A lo largo de toda la obra se descalifica a las dos mujeres asesinadas por Orestes, quien, junto con su hermana, no solo manifiesta una valoración negativa de Helena (1994, vv. 128-131, 246-247), sino que ambos señalan que se trata de una condición común con su hermana Clitemnestra (vv. 1590, 1607). El Coro comparte la apreciación sobre Helena: "para todas las mujeres es digna de odio la hija de Tíndaro, la que deshonró a la raza" (vv. 1153-1154). ${ }^{26}$ En tanto, Pílades estima que se trata de una mujer malvada y eso provocó que su esposo también sea malvado (v. 737) ${ }^{27}$ A esto habría que sumar la descalificación al género femenino llevada adelante por Orestes cuando sostiene que el papel principal en la reproducción es para el hombre. No es un dato menor que a la única mujer que el héroe trágico parece estimar, su hermana, la halague diciendo que posee "una mente masculina" (v. 1204).

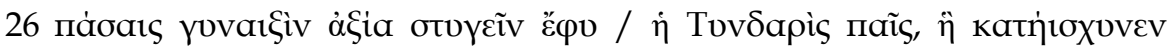
үغ่vos.

27 Sobre el tratamiento literario y filosófico que ha recibido la controvertida figura de Helena, desde Homero hasta la actualidad, véase Bañuls, Do Céu Fialho, López, De Martino, Morenilla, Pociña Pérez, \& Silva (2007) - en el que encontramos un trabajo sobre el personaje en Orestes - ; Bettini \& Brillante (2008) - que dedican un capítulo a su carácter de adúltera-; y Saquero Suárez-Somonte (2014); entre otros. 
Por otra parte, se destaca en numerosas ocasiones el hecho de que Helena había conducido hacia la muerte a un gran número de griegos por haber ocasionado la guerra de Troya.$^{28} \mathrm{Hemos}$ visto que ya en el prólogo Electra menciona el argumento en dos oportunidades (vv. 56-60 y 130-131), y volverá sobre el tema junto con el Coro en el tercer estásimo al escuchar los gritos de Helena cuando era asesinada (vv. 1302-1310). Pílades remite a la devastación de los aqueos ni bien escucha que Helena se encuentra en la ciudad (v. 743) y lo emplea para justificar el crimen. Además de perjudicar a Menelao, el asesinato de la reina otorgará gratitud y gloria a los conspiradores (vv. 1132-1148). Con el objetivo de alentar a Pílades y Orestes a secuestrar a Hermíone, el coro de argivas recuerda las consecuencias que tuvo para la Hélade el abandono de Esparta por parte de Helena (vv. 1361-1365). Por último, el esclavo frigio considera justo que la esposa de Menelao muriese por haber hecho sufrir tanto a los argivos como a los troyanos (v. 1515). La crítica ha interpretado que el personaje expresa una valoración negativa de su ama por temor (Andrade en Eurípides, 2007, pp.179-180). Sin embargo, el esclavo frigio, al lamentarse de la destrucción de su ciudad de origen ante el Coro, que no constituye una amenaza para él, señala que fue ella la causa (1994, vv. 1381-1393). Además, el personaje compara a Pílades con héroes que participaron de la guerra de Troya (vv. 1404-1480) y así refuerza

28 Homero sentó las bases del debate acerca del papel de Helena en el asedio a la ciudad Troya. Véase especialmente el discurso de los ancianos troyanos que la culpan y, en contraste, el de Príamo, que considera como causantes a los dioses (Ilíada 3.156-165). En la Atenas clásica la reflexión se concentró en la responsabilidad personal de Helena y se examinaron todas las implicaciones del adulterio. Así lo hizo Eurípides en Troyanas, donde Menelao tendrá que tomar la decisión de matarla o llevarla consigo a Esparta, y en Helena, tragedia que sigue la versión de Estesícoro en la que Helena nunca fue a Troya, sino que fue llevada a Egipto. Cabe destacar las diferencias en el tratamiento del personaje: en Troyanas, representada en el 415 a. C., Helena no tiene escrúpulos y, gracias a su magnetismo erótico, escapa de la muerte a manos de su marido; en cambio, tres años después en Helena, se la representa como una mujer virtuosa que durante diecisiete años ha sido calumniada sin justificación; por otra parte, los sofistas Gorgias (Encomio de Helena) e Isócrates (Elogio a Helena) retomaron la figura mítica de Helena para expresar sus ideas sobre la retórica. 
el imaginario relativo al enfrentamiento que ocasionó tantas muertes en los dos bandos.

El desprecio tiene dos vertientes que es necesario distinguir y que el psicoanálisis ofrece herramientas para comprender. Por un lado, sobre el odio de Orestes hacia Clitemnestra, el texto ilustra una modalidad que solemos encontrar en la clínica de la psicosis: el desprecio hacia la madre como parte de la tramitación que lleva adelante el sujeto de la hostilidad entre los progenitores. Recordemos el análisis del matricida Pierre Rivière hecho por Foucault (2001/1973), donde se destaca el desprecio hacia la madre y la hostilidad de los progenitores. Si bien no hay que olvidar que se trata de en un caso del siglo XIX y el enfoque se centra en las relaciones de poder y saber, no deja de sorprender la similitud de las coordenadas. En Orestes no hay referencia a los motivos que condujeron a Clitemnestra a asesinar a su marido, que son el sacrificio de Ifigenia (hija de ambos) en Áulide y el regreso de la expedición a Troya con una concubina, Casandra.

Sin embargo, esto no constituye un problema, por dos razones. En primer lugar, el público estaba al tanto de dichos sucesos que formaban parte de la tradición mítica. ${ }^{29}$ Lo cierto es que desde el psicoanálisis se ordena este tipo de silencios en relación con lo impronunciable, en el sentido de que algo no se diga no quiere decir que no esté operando, de modo que resulta un silencio sumamente sonoro. Por otro lado, cabe recordar que entre los argumentos de Orestes para justificar el matricidio se ubica el adulterio. En varios pasajes del monólogo ante Tíndaro se remite al castigo que correspondía a Clitemnestra por "las bodas privadas y no castas" con Egisto (1994, vv. 555-559, 566570 y 572-575). El campesino en la asamblea, cuando intenta defender al joven, retoma la acusación de adulterio: "quiso vengar a su padre matando a una mujer malvada y sin dios" (vv. 924-925). ${ }^{30}$ Como su hermana, Clitemnestra es una mujer malvada. Luego explica que se había convertido en un obstáculo para la comunidad (vv. 926-930).

29 Se trata de cuestiones abordadas en profundidad por Esquilo en Agamenón y por Eurípides en Electra, obras representadas con anterioridad a la que aquí estudiamos. La secuencia del sacrificio de Ifigenia se representa en Ifigenia en Áulide, de Eurípides, producida probablemente con posterioridad a Orestes.

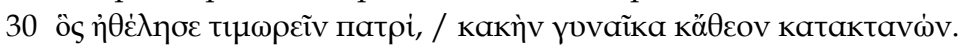


Nadie iba a querer ir a la guerra por temor a que los hombres que se quedaran corrompieran a sus esposas, como lo había hecho Egisto, el amante de la esposa de Agamenón, que no había participado de la expedición a Troya. No olvidemos que, además, el delito de adulterio es compartido con Helena. De modo que podríamos afirmar que ambas son castigadas con la muerte por abandonar el lugar de madre y acercarse al de La Mujer.

No podemos dejar de recordar que Helena era, según los griegos, la mujer más bella del mundo y había sido pretendida por todos los reyes de Grecia. Razón por la que Tíndaro al momento de casarla hizo jurar a todos los presentes que acudirían en auxilio del elegido en caso de que fuese disputada su esposa. El juramento fue recordado por Menelao años después haciendo que todos los reyes griegos partieran a Troya en su ayuda. De modo que Helena posee el estatuto de objeto de deseo por excelencia en el pensamiento griego. Lo cierto es que el riesgo de la seducción lo encontramos en Orestes: Electra teme que Pílades y Orestes desistan del plan acordado fascinados por la belleza de Helena (1994, v. 1287).

Clitemnestra y Helena se ubican a las antípodas de Penélope que, al esperar por su marido en el hogar criando al hijo, parece seguir a Freud que a lo largo de toda su producción considera a la madre como el ideal de feminidad. ${ }^{31}$ Habrá que esperar a Lacan y a la reivindicación de lo femenino que emerge con una fuerza inédita en la segunda mitad del siglo XX para la ruptura de la unidad mujer-madre. ${ }^{32}$ Desde la perspectiva lacaniana es posible comprender el papel que cumplen estas femmes fatales; al traicionar a sus esposos y abandonar a sus hijos, ${ }^{33}$ ambas actúan de un modo inesperado y se convierten en enigmas para los hombres. ${ }^{34}$ Ahora bien, al igual que Medea en

31 Véase, entre otros textos, la conferencia de Freud "La feminidad" (2001/1933, pp. 104-125).

32 Lacan en "Juventud de Gide, o la letra y el deseo" (2002/1966, pp. 740-741). Zafiropoulos (2017b) se ha ocupado de la cuestión femenina desde Freud a Lacan.

33 De acuerdo con la tradición mítica, Clitemnestra había enviado fuera de Argos a Orestes de niño, que regresó para vengar a su padre. En tanto, Helena, al irse a Troya, había abandonado a Hermíone, que fue criada por su hermana.

34 Según la ley ateniense las mujeres estaban siempre bajo el control de un hombre: su marido y, si no estaban casadas, su padre, su hermano o su abuelo (Gould, 
la versión de Eurípides, modelo tomado por Lacan para hablar de la mujer en contra de la madre -que se va de Corinto en un carro alado como una diosa-, Helena es salvada por Apolo y llevada a los cielos. En el caso de Clitemnestra, esta es castigada con la muerte a manos de su hijo, pero en el de Helena se suspende el castigo; así se expresa la ambivalencia característica de la obra de Eurípides en cuanto al papel de la mujer se refiere. ${ }^{35}$

Como sucede en otras obras clásicas, en Orestes se les atribuye mala fama a las mujeres para justificar su castigo. "A ella se la maldice mujer, se la almadice (on la dit-femme, on la diffâme)", resume Lacan (1992/1975, p. 103). Dato con el que nos encontramos de forma literal en boca de Electra: “Tíndaro engendró una notable †a la censura† estirpe de hijas e infame a lo largo de la Hélade" (1994, vv. 249-250). ${ }^{36}$ Entendemos que los asesinatos de Clitemnestra y Helena constituyen lo que en la actualidad consideramos femicidios, definidos por tratarse de crímenes de odio hacia las mujeres. El término femicidio, que traduce el vocablo inglés femicide, se utilizó por primera vez en 1976 ante el Tribunal Internacional sobre Crímenes contra la Mujer en la ciudad de Bruselas, procedimiento que permitió la defi-

1980, p. 43). Para un estado de la cuestión sobre el tema de la mujer en la Antigüedad griega clásica véase Rodríguez Cidre (2010, pp. 25-48), que se enfoca en el género trágico y especialmente en Eurípides.

35 Respecto de los personajes femeninos en las tragedias de Eurípides, véase Powell (1990). En el libro se dedica un capítulo a la figura de Medea (Powell, 1990, pp. 16-31), y otro a la supuesta misoginia del poeta, que es rechazada por la autora del texto (Powell, 1990, pp. 32-75), posición con la que acordamos.

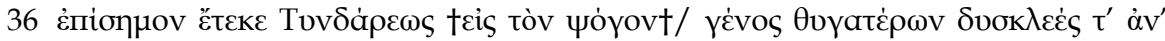

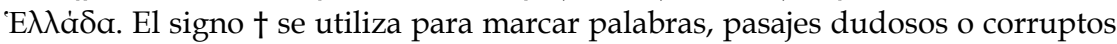
en los manuscritos. Estesícoro (fr. 85, en Davies \& Finglass, 2014), poeta lírico del que se conservan únicamente fragmentos, cuenta en el poema dedicado a Helena que Afrodita castigó a Tíndaro por olvidarla en un sacrificio haciendo que sus hijas fueran infieles a sus maridos. Recuérdese que el anciano era padre biológico solo de Clitemnestra, porque Helena era hija de su esposa con Zeus. Otra versión señala que Helena es el fruto de la unión entre Zeus y Némesis (Apolodoro, Biblioteca, III, X, 7). También Hesíodo en el Catálogo de las mujeres (fr. 176) refiere al castigo de Afrodita sobre las hijas de Tíndaro. El fragmento de Estesícoro y el de Hesíodo constituyen el escolio al v. 249 de Orestes de Eurípides. 
nición de las formas de violencia contra la mujer. ${ }^{37}$ En la década del 90 el concepto se redefinió del siguiente modo: "el asesinato de mujeres por hombres motivado por el odio, desprecio, placer o sentido de posesión hacia las mujeres" (Radford \& Russell, 1992). La definición actual encaja perfectamente con la tragedia donde el odio constituye el móvil primordial del crimen de Helena.

\section{Dos milenios más tarde...}

Los vertiginosos cambios en la tecnología y su impacto en los lazos sociales tradicionales han favorecido en la actualidad una inédita transformación en la consideración de lo femenino y en el posicionamiento de muchas mujeres. Algunas coordenadas arcaicas, sin embargo, se mantienen, se repiten, se acentúan. Sorprende por ejemplo la frecuencia de los femicidios, y nos plantea la pregunta: ¿son más frecuentes, o han dejado de ser un "no-dato" en las estadísticas, como lo eran el divorcio y tantas otras categorías no tenidas en cuenta hasta hace algunas décadas? ${ }^{38}$ Los hechos clínicos que recoge el psicoanalista permiten advertir particularmente hasta qué punto el odio femenino y hacia lo femenino está presente en madres, hombres e hijos.

Recordemos el caso de un joven esquizofrénico que, en tanto tal, típicamente, rechaza al padre que le dio apellido y con el que se crió desde la infancia. Supone además que en verdad ese no es su padre, que su padre es otro, un criminal que las voces le indican. Queda tácito el hecho de que entonces la madre no lo concibió con aquél, sino con este otro hombre. El odio y la violencia del analizante van dirigidos en principio hacia el padre, amplificando en su ideación y en su conducta el discurso lapidario que la madre tiene hacia ese hombre con el que convive desde hace más de 30 años y que aporta el $100 \%$ de los ingresos monetarios de la casa. El camino del análisis lleva, sin

37 Si bien suele utilizarse femicidio, el término específico es feminicidio, cuyo significado es sinónimo.

38 Sobre la no-transmisión y la complejidad en los estudios sobre disolución de las uniones en demografía puede consultarse Masciadri (2006), especialmente capítulo 3, que se aboca al fenómeno en Argentina. 
embargo, a que el rencor del analizante hacia el padre, aún teñido de la tonalidad de la némesis materna, de un modo progresivo vaya virando hacia la madre que, si bien cuida devotamente a su hijo, lo devuelve al campo de batalla parental que incluye injurias cotidianas y descalificaciones cruzadas. La batalla es moral y comercial, ya que la mujer pasa todas las facturas que puede a ese padre, ese hombre que no hace totalmente caso de sus caprichos, de sus exigencias económicas de madre y ama de casa privilegiada por los generosos ingresos del marido -pero no por su deseo-.

La rebelión violenta del paciente se manifiesta en un pasaje al acto en el que golpea al padre, rompe todo lo que encuentra en la casa y es internado. Los padres se separan y el joven vuelve a vivir con su madre. Mantiene desde entonces una relación más cordial pero distante con el padre, al que suele no atender por teléfono ni responder sus mensajes de invitación por otros medios. Luego de un tiempo, comienza a destrozar todo cuanto puede ser señal de independencia de una madre-mujer que dice querer comenzar a hacer su vida, estudiar, trabajar, dar clases. Mientras otros vínculos de la madre se van normalizando, el hijo rompe sistemáticamente los anteojos que a ella le permiten leer; también la escupe, le arranca mechones de pelo, destruye su computadora y los discos externos donde guardaba un back-up de sus archivos. Le hace fuertes reclamos cuando no está o no respeta los horarios; él tampoco los respeta, pero la moral y las buenas costumbres indican que una mujer debe estar en su casa, dormir en los horarios usuales, cocinar, etcétera.

Nos parece notable que lo que inicialmente parece ser la "culpa del padre", que solo aporta plata e intervenciones inadecuadas, según la madre, se va revelando como discurso de una mujer despechada y celosa, que hace uso del hijo enfermo como némesis femenina. El hijo, a su vez, se venga de manera sistemática de las manifestaciones de lo que en ella puede haber de independencia femenina y de desamor hacia el padre de sus hijos. Estos coinciden en que "la loca" es esa mujer, y que es ella quien debería dejar hacer su vida al hijo enfermo, al que solo cuida como rehén de un amor perdido. En el último tiempo, la violencia del hijo se expresa con relación a su madre y a una hermana de ella, de quien se dice que es "muy atractiva"; se trata de una mujer que en la adolescencia temprana del analizante, según relata éste, se 
paseaba semidesnuda ante él y lo invitaba a dormir la siesta. Nuestra interpretación de las coordenadas de este caso, que es similar a tantos otros en la actualidad, resulta de una convergencia notable con aquellas descriptas en la tragedia Orestes. Encontramos un sujeto tan loco como Orestes, que se ubica como defensor de las buenas costumbres y expresa un llamativo odio hacia la mujer desdoblado en dos figuras femeninas.

\section{Conclusiones}

En el presente trabajo se ha defendido la hipótesis de que en la tragedia Orestes el odio hacia la mujer constituye el antecedente de la acción trágica por formar parte del argumento que justifica tanto la ejecución del matricidio como la del asesinato de Helena. La conceptualización psicoanalítica acerca de la mujer nos ha permitido comprender el papel de Clitemnestra y su hermana Helena dentro de la trama. Las reverberaciones con la actualidad no fueron difíciles de establecer; retomamos el caso de un joven esquizofrénico que en principio dirigía todo su desprecio al padre, sin embargo, con el correr del análisis vemos al paciente sumamente preocupado por la moral y las buenas costumbres que, según él, su madre no respeta $\mathrm{y}$, como Orestes, debe defender. La violencia hacia la mujer, manifestada en numerosos ataques hacia su madre, encuentra un nuevo objeto en otra figura femenina de la familia, su tía, quien, como una Helena de la actualidad, es una mujer atractiva y sensual.

\section{Bibliografía}

Aélion, R. (1983). Euripide heritier d'Eschyle, Vol. II. Paris, France: Les Belles Lettres.

Aristóteles. (1964). Ars rhetorica. (W. D. Ross, Ed.). Oxford, United Kingdom: University Press.

Aristóteles. (1965). De arte poetica liber. (R. Kassel, Ed.). Oxford, United Kingdom: University Press. 
Assaël, J. (1993). Intellectualité et théâtralité dans l'oeuvre d'Euripide. Nice, France: Assocciation des Publications de la Faculté des Lettres, Arts et Sciences Humaines.

Bañuls, J. V., Do Céu Fialho, M., López, A., De Martino, F., Morenilla, C., Pociña Pérez, A. \& Silva, M. de F. (Eds.) (2007). O Mito de Helena de Tróia à Actualidade, Vol. I. Coimbra, Portugal: Universidade de Coimbra, Università di Foggia, Universidad de Granada, Universitat de Valencia.

Bettini, M. y Brillante, C. (2008). El mito de Helena. Imágenes y relatos de Grecia a nuestros días. Madrid, España: Akal.

Bunker, H. A. (1944). Mother-Murder in Myth and Legend. The Psychoanalytic Quarterly, 13, 198-207.

Ciani, M. G. (1974). Lessico e funzione della follia nella tragedia greca. Bollettino dell'Istituto di filologia greca, 1, 70-110.

Clarke-Kosak, J. (2004). Heroic Measures. Hippocratic Medicine in the Making of Euripidean Tragedy. Leiden, Netherlands: Brill.

Davies, M. \& Finglass, P. J. (2014). Stesichorus. The Poems. Cambridge, United Kingdom: University Press.

Dracoulides, N. (1952). La généalogie des Atrides et l'aventure d'Orestes. Psyche, 7, 805-817.

Eurípides. (1965). Orestes. (V. Di Benedetto, Ed.). Firenze, Italia: La Nuova Italia.

Eurípides. (1994). Euripidis Fabulae, Vol. III. (J. Diggle, Ed.). Oxford, United Kingdom: University Press.

Eurípides. (2001). Oreste. (E. Medda, Ed. y trad.). Milano, Italia: BUR.

Eurípides. (2007). Orestes. (N. Andrade, Trad.). Buenos Aires, Argentina: Losada.

Ferrini, M. F. (1978). Tragedia e patologia: lessico ippocratico in Euripide. Quaderni Urbinati di Cultura Classica, 29, 49-62.

Foucault, M. (2001/1973). Yo, Pierre Rivière, habiendo degollado a mi madre, a mi hermana y a mi hermano. Barcelona, España: Tusquets.

Freud, S. (2001/1917). 21 a conferencia. Desarrollo libidinal y organizaciones sexuales. En J. Strachey (Ed.), J.L. Etcheverry \& L. Wolfson (Trads.). Obras Completas (Vol. XVI, pp. 292-308). Buenos Aires, Argentina: Amorrortu.

Freud, S. (2001/1933). 33 conferencia. La feminidad. En J. Strachey (Ed.), J. L. Etcheverry \& L. Wolfson (Trads.). Obras Completas (Vol. XXII, pp. 104-125). Buenos Aires, Argentina: Amorrortu.

Freud, S. (2001/1939). Moisés y la religión monoteísta. En J. Strachey (Ed.), J. L. Etcheverry \& L. Wolfson (Trads.). Obras Completas (Vol. XXIII, pp. 1-132). Buenos Aires, Argentina: Amorrortu. 
Gambon, L. (2016). La invención de la locura de los héroes: acerca de las locuras trágicas en la antigüedad griega. En Gambon, L. (Coord.), A quien Dionisos quiere destruir... La tragedia y la invención de la locura (pp. 25-52). Bahía Blanca, Argentina: EdiUNS.

Gould, J. (1980). Law, Costum and Myth: Aspects of the Social Position of Women in Classical Athens, Journal of Hellenic Studies, 100, 38-59.

Green, A. (1982/1969). Orestes y Edipo: del oráculo a la ley. En El complejo de Edipo en la tragedia (pp. 61-133). Barcelona, España: Ediciones Buenos Aires.

Greenberg, N. A. (1962). Euripides' Orestes: An Interpretation. Harvard Studies in Classical Philology, 66, 157-192.

Héritier, F. (2007). Masculino/Femenino II. Disolver la jerarquía. México: Fondo de Cultura Económica.

Holmes, B. (2010). The Symptom and the Subject. Princeton, United States of America: University Press.

Homero. (1963). Homeri Opera. Odyssey libros continens XIII-XXIV, t. IV. (D. B. Monro \& T. W. Allen, Eds.). Oxford, United Kingdom: Clarendon Press.

Homero. (1988). Homeri Opera. Iliadis libros I-XXIV continens, t. I y II. (D. B. Monro \& T. W. Allen, Eds.). Oxford, United Kingdom: Clarendon Press.

Klein, M. (1976/1963). Algunas reflexiones sobre "la Orestiada". En Obras Completas, (Vol. VI, pp. 191-218). Buenos Aires, Argentina: Paidós.

Lacan, J. (1974-1975). El Seminario. Libro 22. R. S. I. No publicado. Recuperado de http://www.bibliopsi.org/docs/lacan/27\%20Seminario $\% 20$ 22.pdf.

Lacan, J. (1992/1973). El seminario de Jacques Lacan, Libro 7: La ética del psicoanálisis (D. Rabinovich, Trad.). Buenos Aires, Argentina: Paidós.

Lacan, J. (1992/1975). El seminario de Jacques Lacan, Libro 20: Aún. (Cevasco, R. \& Mira Pascual, V., Trads.). Buenos Aires, Argentina: Paidós.

Lacan, J. (1998/1975). El seminario de Jacques Lacan, Libro 1: Los escritos técnicos de Freud. (Rabinovich, D., Delmount-Mauri \& Sucre, J., Trads.). Buenos Aires, Argentina: Paidós.

Lacan, J. (2001/1969). L'acte psychanalytique". En Autres Écrits (pp. 375383). Paris, France: Seuil.

Lacan, J. (2001/1972). L'étourdit. En Autres Écrits (pp. 449-495). Paris, France: Seuil.

Lacan, J. (2002/1966). Escritos 2. (T. Segovia, Trad.). Buenos Aires, Argentina: Siglo Veintiuno Editores.

Lorenzi, P. (2015). La follia di Oreste. Psicopatologia di un personaggio del mito. Roma, Italia: Alpes Italia. 
Masciadri, V. (2006). Tendencias en la constitución y disolución de las uniones en la Argentina (1947-2001). (Tesis de doctorado no publicada). Córdoba, Argentina: Facultad de Ciencias Económicas, Universidad Nacional.

Mc. Hardy, F. (2008). What Motivates Orestes? En Revenge in Athenian Culture (pp. 103-117). London, United Kingdom: Duckworth.

Merkelbach, R. \& West, M. L. (1967). Fragmenta Hesiodea. Oxford, England: University Press.

Padel, R. (2005/1995). A quien los dioses destruyen. Elementos de la locura griega y trágica. México: Sexto Piso.

Powell, A. (1990). Euripides Women and Sexuality. London, United Kingdom: Routledge.

Radford, J. \& Russell, D. (1992). Femicide. The Politics of Woman Killing. New York, E.U.: Twayne Publishers.

Rodríguez-Cidre, E. (2010). Cautivas troyanas. El mundo femenino fragmentado en las tragedias de Eurípides. Córdoba, Argentina: Ordia Prima.

Saquero Suárez-Somonte, P. (2014). Helena de Troya: una heroína controvertida. Asparkía, 25, 113-126.

Simon, B. (1984). Razón y locura en la antigua Grecia. Madrid, España: Akal. Slater, P. (1971). The Glory of Hera. Greek Mythology and the Greek Family. Boston, United States of America: Beacon Press.

Soler, C. (2010). Dos afectos. Conferencia dictada en la Facultad de Psicología, Universidad de Buenos Aires. No publicada.

West, M. L. (1966). Hesiod, Theogony. Oxford, United Kingdom: Clarendon Press.

Willink, C. W. (1986). Euripides, Orestes. Oxford, United Kingdom: Clarendon Press.

Zafiropoulos, M. (2010). Lacan l'Helléniste. Recherches en psychanalyse, $9(1), 46-54$.

Zafiropoulos, M. (2017a). Les mythologiques de Lacan. La prison de verre du fantasme: Edipe roi, Le diable amoureux, Hamlet. Paris, France: Editions érès.

Zafiropoulos, M. (2017b). La cuestión femenina de Freud a Lacan. La mujer contra la madre. Buenos Aires, Argentina: Editorial Logos Kalós.

Zeitlin, F. (1981). The Closet of Masks: Role-Playing and Myth-Making in the Orestes of Euripides. Ramus, 9, 51-77. 